\title{
STRES MAHASISWA DITINJAU DARI KOPING RELIGIUS
}

\author{
STUDENT STRESS IN TERMS OF RELIGIOUS COPING
}

Oleh:

Ratna Supradewi ${ }^{1}$

\begin{abstract}
ABSTRAK
Pada kehidupan sehari-hari, individu akan dihadapkan pada stresor yang dapat menyebabkan stres, demikian pula dengan kehidupan mahasiswa. Peran mahasiswa yang harus mengikuti dan menyelesaikan tugas-tugas akademis dapat menjadi stresor tersendiri yang dapat mengakibatkan mahasiswa menjadi stres. Salah satu cara mengelola stres adalah dengan melakukan koping. Penelitian ini bertujuan untuk menguji hubungan koping religiusdengan stres yang dialami mahasiswa. Subjek penelitian ini adalah mahasiswa semester enam fakulas psikologi Universitas Islam Sultan Agung, yang berjumlah 77 orang. Teknik pengambilan sampel yang digunakan adalah purposive sampling. Skala yang dipakai dalam penelitian ini adalah skala koping religius dan skala stres. Uji hipotesis yang digunakan pada penelitian ini menggunakan analisis non parametrik dari Spearman dikarenakan sebaran data tidak memenuhi uji normalitas. Dari hasil uji hipotesis peroleh nilai korelasi $r=-0,280$ dengan taraf signifikansi $p=$ 0,014 ( $p>0,05$ ) sehingga dapat disimpulkan ada hubungan negatif yang signifikan antara koping religius dan stres mahasiswa. Artinya semakn tinggi koping religius yang dilakukan mahasiswa maka semakin rendah stres yang dialaminya dan sebaliknya.
\end{abstract}

Kata Kunci:Koping Religius; Stres; Mahasiswa

\begin{abstract}
In everyday life individuals will be faced with stressors that can cause stress, as well as student life. The role of students who must follow and complete academic tasks can be a stressor that can cause students to become stressed. One of the ways to manage stress is coping. This study aims to examine religious coping relationships with stress experienced by students. The subjects of this study were sixth semester students in psychology at Sultan Agung Islamic University, which numbered 77 people. The sampling technique used was purposive sampling. The scale used in this study is the scale of religious coping and stress scale. The hypothesis test used in this study used non-parametric analysis from Spearman because the distribution of data did not meet the normality test requirements. From the results of the hypothesis testing obtained the correlation value $r=-0.280$ with a significance level $p=0.014(p>0.05)$ so it can be concluded that there is a significant negative relationship between religious coping and student stress. It means that the higher level of religious coping done by students, the lower the stress they experience and vice versa.
\end{abstract}

Keywords:Religious Coping; Stress; College Student

\section{PENDAHULUAN}

Masalah stres pada mahasiswa perlu mendapatkan tanggapan dan perhatian yang serius. Menurut Fink, (2003) generasi pada masa sekarang telah

${ }^{1}$ FakultasPsikologiUniversitas Islam Sultan Agung Semarang, ratnavina4@gmail.com 
dihadapkan pada tantangan yang lebih besar dibandingkan dengan generasi sebelumnya. Syukur (2008) mengungkapkan, ketegangan psikososial yang terjadi di tengah masyarakatpun juga semakin meningkat karena adanya azab dan sengsara yang disebabkan oleh mordernisasi (the agony of mordernization). Hal tersebut antara lain ditandai dengan tingginya angka kriminalitas, kehilangan makna dari tujuan hidup, kenakalan remaja, pergeseran nilai-nilai kehidupan, depresi dan stres yang dirasakan dalam kehidupan sehari-hari.

Demikian pula dengan kehidupan mahasiswa. Pada era sekarang, mahasiswa dituntut untuk dapat menghadapi problem-problem yang muncul di hadapannya dengan lebih tangguh. Ketatnya persaingan dalam mencapai prestasi, kemampuan beradaptasi dengan lingkungan pergaulan kampus, serta tugas-tugas perkuliahan merupakan sebagian permasalahan yang harus dihadapi mahasiswa. Tanggung jawab yang harus dilaksanakan sebagai mahasiswa dapat merupakan stresor.Mahasiswa yang diharapkan dapat berperan sebagai calon pemimpin bangsa di masa yang akan datang perlu mempunyai kesehatan mental yang baik. Hawari (2003) mengemukakan bahwa APA (American Psychological Association, 1992) telah menetapkan kesehatan mental dipandang dari "biopsycho-socio-spiritual". Artinya manusia dipandang sehat secara mental dari segi fisik, psikis, sosial, dan spiritual.

Mahasiswa adalah sekelompok individu yang sedang menuntut ilmu di Perguruan Tinggi. Menjadi mahasiswa berarti perlu melakukan adaptasi. Tidak semua mahasiswa mampu melakukan adaptasi dengan lancar dalam menyelami problematika kehidupannya. Bagi mahasiswa yang tidak dapat menyelami problematika kehidupannya dengan baik, maka akan menimbulkan stres. Siswanto (2002) dan Lerik (2004) mengungkapkan stresor-stresor yang biasa dihadapi oleh mahasiswa, yaitu: 1) Tingginya tuntutan akademik. Tugas-tugas kuliah, praktikum yang harus dilakukan seringkali mengandung instruksi yang kompleks, waktu yang sempit, dan tingkat kesulitan yang cukup tinggi sehingga situasi yang terjadi dapat mengancam integritas individu, 2) Perubahan tempat tinggal, dari yang tinggal bersama orang tua menjadi tinggal bersama orang lain. Misalnya kost, kontrak atau tinggal di tempat saudara. Di sini berarti mahasiswa perlu belajar untuk mengurus kebutuhannya sendiri, menatur keuangan sebaikbaiknya dan menentukan prioritasnya secara tepat, 3) Pergantian teman sebagai akibat dari perpindahan tempat tinggal atau tempat studi, perubahan relasi dari yang bersifat pribadi menjadi lebih bersifat fungsional. Penyesuaian dalam pergaulan, mencari sahabat baru, dan menjajagi kesempatan-kesempatan baru dalam aktivitas, 4) Perubahan budaya asal dengan budaya tempat tinggal yang baru, menyesuaikan dengan masyarakat dengan masyarakat sekitar dan normanorma yang berlaku, 5) Penyesuaian dengan jurusan yang dipilih. Bagi yang menyukai pilihannya merasa cocok serta tidak kesulitan dalam mengikuti perkuliahan tidak akan menimbulkan masalah yang berarti. Sementara bagi mahasiswa yang merasa "salah jurusan", kurang cocok, merasa kesulitan dalam mengikuti perkuliahan akan menimbulkan masalah yang besar, 6) Mulai memikirkan dan mempersiapkan karir yang ingin ditempuh dan mencari pekerjaan setelah lulus nanti. 
Kondisi psikologis mahasiswa yang tidak menyenangkan dapat terefleksikan dengan beberapa cara, seperti: depresi, kecemasan, stres dan gangguan tidur (Lejoyeux et.al., 2011; Schraml et.al., 2011;Feld \& Shusterman, 2015). Konsep stres secara luas diasosiasikan meliputi segala aspek kesulitan hidup, termasuk ketidaknyamanan psikologis. Setiap siswa menghadapi stres yang sama secara berbeda (Boujut, 2007). Stres dapat mengganggu performa prestasi mahasiwa sehingga mengakibatkan buruknya nilai akademis (Pariat, et.al., 2014). Stres juga menyebabkan mahasiswa menghindari interaksi sosial, berkurangnya produktivitas, lebih banyak membuat kesalahan, absen dari kuliah, kehilangan minat atau apati, sering gugup, menyalahkan orang lain, terganggunya ritme tidur, bermusuhan, marah, mudah emosional, dan menangis (Misra \& McKean, 2000; Pariat, et. al. 2014).

Stresor tidak selalu menimbulkan stres pada individu, bahkan untuk stresor yang sama belum tentu akan menyebabkan akibat yang sama pada individu (Prawitasari dalam Supradewi, 2006). Individu yang mengalami stres akan terlihat dari munculnya respon emosional, kognitif, dan fisiologis. Contohnya mudah cemas, tersinggung, marah, jantung berdebar-debar, sakit perut dan lainlain(Crider et.al.,1983).Pengelolaan stres memang berkaitan dengan seperangkat daya dukung yang dimiliki individu, salah satunya adalah koping yang dilakukannya.

Koping merupakan suatu proses yang dipengaruhi oleh pemikiran atau pemahaman individu masing-masing tentang hubungannya dengan lingkungan. Cara tiap individu untuk mengatasi masalahnya berbeda-beda, tergantung penilaian individu dengan lingkungan dan juga tergantung pada sumber daya yang tersedia, serta kendala yang menghambat penggunaan sumber daya tersebut (Lazarus \& Folkman, 1984). Rice (1999) mengemukakan koping adalah suatu upaya yang dilakukan untuk mencegah, menghilangkan, mengurangi stresor, atau menolerir efek dari stres dengan bahaya minimum. Lazarus \& Folkman ( 1984) mengemukakan bahwa koping yang terfokus pada emosi (emotion focused coping/ EFC) terkadang dapat membawa hasil yang kurang baik terutama untuk tujuan jangka panjang, tetapi merupakan jenis koping yang cukup berhasil untuk meredakan stres. Bahkan pada beberapa situasi tertentu koping yang terfokus pada emosi diperlukan dan lebih efektif untuk meredam stres secara langsung. Menurut Taylor (1995) koping apapun bentuknya, baik koping yang terfokus pada problem (Problem Focused Coping/ PFC) maupun koping yang terfokus pada emosi (Emotion Focused Coping/ EFC) bila dapat meredakan ketegangan yang dialami maka koping tersebut dapat dikatakan efektif. Koping dikatakan efektif bila dapat menjaga keseimbangan individu selama mengalami stres.

\section{STRES}

Stres merupakan istilah yang ambigu yang digunakan dengan berbagai cara untuk menggambarkan situasi, objek atau orang yang menyebabkan stres, perasaan dan respon fisik yang terjadi pada individu, dan hasil yang diakibatkan berupa perilaku, kognisi, atau fisiologis (Hayward dalam Curtis, 2000). Curtis (2000) mengungkapkan perlu dibedakan antara stresor, respon stres, dan stres. 
Stresor adalah peristiwa atau kejadian yang dipersepsi individu sebagai membahayakan fisik atau kesejahteraan psikologisnya. Dalam hal ini dapat berupa hal-hal yang bersifat internal, (misal: sakit), eksternal (misal: perubahan lingkungan, seperti panas, kepadatan atau kebisingan), atau sosial (misal: harus menyampaikan suatu pidato). Respon stres mengacu pada reaksi terhadap peristiwa atau kejadian yang melibatkan perubahan-perubahan jasmani yang dipersiapkan untuk keadaan darurat (respon melawan atau lari) maupun reaksireaksi psikologis seperti: cemas, marah, dan agresi, apati dan depresi, serta pelemahan kognitif. Dengan demikian stres merupakan keadaan yang disebabkan oleh stresor, menghasilkan respon-respon stres yang digunakan secara efektif untuk mengatasi situasi yang tidak menyenangkan tersebut.

Perubahan atau transisi kehidupan dapat mengakibatkan seseorang menjadi stres (Sarafino, 1998). Salah satu perubahan kehidupan adalah beralihnya masa sekolah SMU kemudian menjadi mahasiswa. Peran sebagai mahasiswa menuntut tanggung jawab yang lebih besar daripada ketika SMU. Lebih lanjut menurut Sarafino (1998) perubahan kehidupan pada seseorang menuntut kemampuan orang tersebut untuk beradaptasi secara fisik, psikis, maupun sosial. Bila terlalu banyak tuntutan untuk beradaptasi yang dirasa mengancam kesejahteraan, dan individu tidak dapat mengatasinya maka muncullah reaksi stres. Hardjana (2002) mengemukakan dalam peristiwa stres sekurang-kurangnya ada tiga hal yang saling terkait, yaitu: hal, peristiwa, orang, keadaan yang menjadi sumber stres (stressor); orang yang mengalami stres (the stressed); dan hubungan antara keduanya yang merupakan transaksi (transactions).

Crider et.al. (1983) berpendapat bahwa individu yang mengalami stres akan memberikan respon yang bersifat :

1) Respon emosional. Individu yang mengalami stres hampir selalu menampakkan emosi negatif atas masalahnya, berupa cemas, mudah tersinggung, marah, gelisah, depresi, dan perasaan bersalah.

2) Respon kognitif. Respon kognitif muncul dalam empat bentuk, yaitu : a) Gangguan fungsi pikir. Cara berpikir individu ketika tidak sedang stres adalah rasional, logis, dan fleksibel. Namun ketika dalam keadaan stres kemampuan untuk mengorganisasi pikiran secara logis dan koheren terganggu, b) Gangguan kesan mental. Individu. Individu sering terganggu oleh pikiran-pikiran obsesif, kesan-kesan kegagalan dan ketidakmampuan diri, kesan-kesan yang tidak menyenangkan, mimpi buruk yang menakutkan, c) Gangguan konsentrasi. Dalam keadaan stres, kemampuan individu untuk berkonsentrasi akan berkurang atau melemah. Konsentrasi yang lemah mengganggu performa dan kemampuan individu dalam memecahkan masalah, d) Gangguan daya ingat. Daya ingat mudah kacau, mudah lupa, sert berkurangnya kemampuan memecahkan masalah.

3) Respon fisiologis. Respon fisiologis dibagi dua, yaitu : a) Simtom otot skeletal, meliputi ketegangan, kelelahan, dan sakit, b) Simtom organ dalam meliputi jantung berdebar, sering buang air besar,sakit perut, sesak nafas, kaki dan tangan menjadi dingin. 


\section{KOPING RELIGIUS}

Penelitian Abraido-Lanza et.al. (2004) mengemukakan bentuk koping yang lain dalam pengelolaan stres, yaitu koping yang bersifat religius (religious coping). Koping religius meliputi menggunakan kognitif atau strategi perilaku yang didasarkan pada kepercayaan dan praktek-praktek religi (misal: berdoa, mencari ketenangan atau kekuatan dari Tuhan). Beberapa studi menemukan bahwa koping religius mempunyai efek positif pada mental dan kesehatan fisik selama periode yang penuh stres. Pargament (1997) mengemukakan koping religius memiliki pengertian yang berkenaan dengan cara individu menggunakan kepercayaan agamanya dalam menyelesaikan problem-problem yang dihadapi.

Koping religius mempunyai efek yang positif dan dapat digunakan dalam pengelolaan stres. Berkaitan dengan mahasiswa, mahasiswa yang umumnya berusia 18 sampai 24 tahun pada perkembangan religiusitasnya menurut Shelton (1995) telah memasuki tahap reflektif-individuatif (individuative-reflective). Lebih lanjut menurut Shelton (1995) tahap ini dialami individu pada umur 17-18 tahun dan berakhir usia 20-22 tahun. Pada tahap reflektif-individuatif, mereka mulai dapat mempertanggungjawabkan ungkapan iman yang masuk akal dan logis. Iman mereka lebih konstan dan koheren. Mereka juga mulai memasuki tahap transendental. Pada tahap ini, apa yang diterima sebagai sesuatu yang berharga tidak hanya berasal dari kitab suci dan pendapat ahli, melainkan suasana batiniah yang berhubungan dengan transendental. Subjek merasakan kedekatan dengan Tuhan, merasakan bahwa Tuhan menolongnya.

Religi dapat menjadi bagian sentral dari konstruksi koping. Agama secara signifikan memberi dampak pada proses multidimensional. Agama dikatakan dapat mengurangi atau mencegah stres kehidupan.Agama juga mempunyai dampak positif pada kesehatan mental (Pargament,1997).Koping religious adalah koping yang melibatkan penggunaan kognisi dan strategi perilaku yang didasarkan pada kepercayaan atau praktek-praktek religius untuk mengelola stress emosional atau ketidaknyamanan fisik (Koenig, 1994). Koping religius melibatkan berbagai cara orang-orang menggunakan religi dan kepercayaan mereka untuk mengelola situasi yang penuh stres. Pargament telah menjadi peneliti utama di bidang koping religious sejak diterbitkan bukunya pada tahun 1997 "The Psychology of Religion and Coping", dan banyak studi telah dilakukan mengenai dampak koping religius terhadap kesejahteraan psikologis (Aflakseir \&Coleman, 2011). Pargament et.al. (1998)mengidentifikasikan 3 cara koping religius, yaitu: self directing, deffering, dan collaborative. Padastrategi self directing individu dibantu tindakannya dalam memecahkan masalahnya. Individu yang yang menggunakan strategi ini memandang dirinya sebagai orang yang diberi Tuhan kemampuan dan sumber-sumber untuk memecahkan masalah. Pada strategi deffering, Tuhan mengatur strategi dalam memecahkan individu secara aktual. Individu bergantung kepada Tuhan dalam memberikan tanda-tanda/ isyarat untuk mengatakan kepada individu pendekatan pemecahan masalah yang akandigunakan. Strategi collaborative merupakan strategikoping yang paling 
umum, dalam hal ini individu dan Tuhan tidak memainkan peran yang pasif dalam proses pemecahan masalah, tetapi keduanya bersama-sama memecahkan masalah individu (Alflakseir \& Coleman, 2011). Pargament, Koenig, dan Perez (2000) berpendapat bahwa koping religius tidak menduplikasi koping non religius dan koping religius mengukur secara berkesinambungan untuk memprediksi hasilhasil yang bervariasi pada stresor kehidupan setelah menghapus efek dari pengukuran koping non religius.

Banyak studi mengenai koping religius telah dilakukan di negara-negara yang didominasi budaya yahudi-kristen. Namun studi tentang koping religius juga dilakukan pada muslim. Ada penekanan dalam literatur Islam tentang keyakinan agama dan praktek-praktek religi dapat digunakan sebagai sumber daya untuk menghadapi kesulitan hidup. Islam mengajarkan orang untuk bersabar, berdoa, percaya dan kembali kepada Tuhan saat membutuhkan bimbingan dan pertolongan. Kepercayaan Islam juga memberi individu penafsiran yang bermakna saat menghadapi situasi sulit. Qur'an menekankan secara jelas bahwa kesulitan-kesulitan di dunia adalah untuk menguji orang-orang yang beriman dan meminta mereka untuk bersabar saat menghadapi permasalahan-permasalan yang datang. Sebagai contoh, Qur'an,surat Al-Baqarah (2) ayat 155 mengatakan: "Kami mengujimu dengan sedikit ketakutan, kelaparan, dan kekurangan harta, jiwa dan buah-buahan, tetapi berikanlah kabar gembira pada mereka yang sabar dalam menghadapi kesulitan". Menurut ajaran religius, peristiwa-peristiwa negatif dalam hidup mempunyai tujuan dan orang-orang diminta bersabar untuk mencapai pertumbuhan spiritual. Berbagai sumber religi Islam, khususnya AlQur'an, memberikan pengarahan tertentu agar perasaan menjadi lebih baik dan mengatasi kesulitan dengan mengingat Tuhan/ berdzikir. Salah satu contoh, di dalam Al-Qur' an surat Al-Baqarah (2) ayat 152 disebutkan, " Ingatlah Aku, maka Aku akan mengingatmu" (Alflakseir \& Coleman, 2011).

Beberapa studi mengenai koping religiuspada populasi muslim telah dilakukan (Ghorbani, Watson \& Khan, 2007; Khawaja, 2008). Kesselring dan kolega (1986) membandingkan penggunaan koping religius antara orang-orang Mesir dan Swedia yang menderita kanker. Dilaporkan bahwa 92\% pasien kanker Mesir menyuarakan keyakinan bahwa Tuhan akan membantu mereka, dibandingkan hanya $37 \%$ pasien kanker Swedia yang menyatakan hal yang sama. Mehta (1997) dalam studi kualitatif pada penduduk muslim yang sudah tua di Malaysia melaporkan bahwa para lansia mengkaitkan proses penuaan mereka dan penurunan fisik yang menyertainya sebagai kehendak Tuhan. Beberapa responden juga menyebutkan mereka membaca ayat-ayat Al-Qur'an untuk mengelola rasa sakit kepala yang mereka alami.

Telah ada beberapa studi untuk mengembangkan pengukuran koping religius untuk muslim.RCOPE (Religious Coping Scale) dikembangkan oleh Khan \& Watson (2006) dengan subjek muslim Pakistan. Kemudian Jana-Masri dan Priester (2007) mengembangkan RoIS (Religiosity of Islam Scale), instrumen berbasis Al-Quran untuk mengukur religiusitas Islam. PMIR (Psychological Measure of Islamic Religiousness) alat lain yang didesain untuk mengukur praktek-praktek dan kepercayaan dalam Islam dikembangkan oleh Abu Raiya, 
Pargament, Stein, \& Mahoney (2008). RCOPE (Religious Coping Scale) dilembangkan oleh Alflakseir dan Coleman (2011) dengan subjek muslim Iran.Terdiri dari praktek religius (religious practise), perasaan negatif terhadap Tuhan (negative feeling toward God), penilaian kembali kebajikan (benevolent reappraisal), strategi koping religius pasif (passive religious coping strategy), dan strategi koping religius aktif (active religious coping strategy) yang semua aiemaitemnya disesuaikan dengan konteks Islam.

Tujuan Penelitian ini untuk mengetahui stres mahasiswa ditinjau dari koping religius.

\section{METODE PENELITIAN}

\section{Variabel Penelitian}

Variabel yang terlibat pada penelitian ini adalah kopingreligius sebagai variabel bebas dan stress sebagai variabel terikat.

\section{Subjek Penelitian}

SubjekpenelitianiniadalahmahasiswaFakultasPsikologiUnissula

Semarang, semester VI (enam), berusiaantara 18 sampai 21 tahunberjumlah 77 orang.

Sarwono

mengemukakanrentangusiatersebuttermasukkelompokusiaremajaakhir.

Pengambilansampelpadapenelitianinimenggunakanteknik purposive sampling, yaituteknikpengambilansekelompoksubjek yang didasarkanatasciri-ciriatausifatsifattertentu yang dipandangmempunyaisangkutpaut yang eratdenganciriciriatausifat-sifatpopulasi yang telahdiketahuisebelumnya (Hadi, 2000).

\section{Instrumen Pengumpulan Data}

Teknikpengumpulan data

menggunakanskalastresdanskalakopingreligius.SkalastresmemakaiskalaSuprade wi (2006) yang mengacupadaresponstres yang dikemukakan Crider (1983) terdiridariaspek 1) responemosi, 2) responfisiologis, 3) responkognitif. Skalastresberjumlah 49 denganindeksdayabedaaitemberkisar 0,269 sampai 0,586 denganestimasireliabilas Alpha sebesar 0,913. Skalakopingreligiusmemakai RCOPE Alflakseirdan Coleman (2011) yang telahdiadaptasiberjumlah 22 aitem, denganestimasireliabilitasmasing-masingsubskala, 0890 untukpraktekreligius, 0,790 untukperasaanperasaannegatifterhadapTuhan, $\quad 0,790$ untukpenilaiankembalikebajikan, $\quad 0,720$ strategikopingpasif, dan 0,790 untukstrategikopingaktif.

\section{Metode Analisis Data}

Uji hipotesis yang digunakan pada penelitian ini menggunakan analisis nonparametrik dari Spearman dikarenakansebaran data tidakmemenuhiujinormalitas.

\section{HASIL DAN PEMBAHASAN}


Analisis data dilakukan dengan menggunakan SPSS 16. Sebelumnya dilakukan uji asumsi yang berupa uji normalitas data dan uji liniearitas. 
RATNASUPRADEWI,Stres Mahasiswa Ditinjau dari Koping Religius

Tabel 1.HasilAnalisisUjiNormalitas

\begin{tabular}{cccccc}
\hline Variabel & Mean & $\begin{array}{c}\text { Standar } \\
\text { Deviasi }\end{array}$ & KS-Z & Sig & Keterangan \\
\hline Stres & 102,68 & 13,5 & 0,078 & $0,200>0,05$ & Normal \\
\hline $\begin{array}{c}\text { Koping } \\
\text { religius }\end{array}$ & 15,74 & 5,98 & 0,113 & $0,017<0,05$ & $\begin{array}{c}\text { Tidak } \\
\text { Normal }\end{array}$ \\
\hline
\end{tabular}

Berdasarkan uji normalitas terhadap skala stres diperoleh nilai $\mathrm{KS}-\mathrm{Z}=$ 0,078 dengan taraf signifikasi $0,200(p>0,05)$. Hasil ini menunjukkan bahwa sebaran data stres terdistribusi normal. Sedangkan uji normalitas terhadap skala koping religius diperoleh nilai $\mathrm{KS}-\mathrm{Z}=0,113$ dengan taraf signifikansi 0,017 $(\mathrm{p}<0,05)$, hal ini menunjukkan sebaran data koping religius tidak terdistribusi normal.

Berdasarkan uji linieritas antara stres dan koping religius diperoleh koefisiensi Flinier sebesar 8,178 dengan taraf signifikan $p=0,005(\mathrm{p}>0,05)$. Hasil tersebut menunjukkan tidak ada hubungan linier antara variabel stres dan koping religius.

Dari hasil uji normalitas diketahui data koping religius tidak terdistribusi normal, dan dari uji linieritas data stres dan koping religius tidak menunjukkan hubungan yang linier. Dalam hal ini untuk menguji hipotesis maka dilakukan analisis non parametrik dari Spearman.Dari hasil uji hipotesis non parametrik Spearman diperoleh nilai korelasi $r=-0,280$ dengan taraf signifikansi $p=0,014$ ( $p>0,05)$ sehingga dapat disimpulkan ada hubungan negatif yang signifikan antara koping religius dan stres mahasiswa. Artinya semakin tinggi koping religius yang dilakukan mahasiswa maka semakin rendah stres yang dialaminya dan sebaliknya.

Berdasarkan hasil uji hipotesis diperoleh nilai korelasi $r=-0,280$ dengan taraf signifikansi $\mathrm{p}=0,014(\mathrm{p}>0,05)$ dengan menggunakan analisis non parametrik dari Spearman yang telah dilakukan maka hipotesis dalam penelitian ini diterima, yaitu terdapat hubungan negatif yang signifikan antara koping religius dan stres pada mahasiswa. Artinya semakin tinggi koping religius yang dilakukan mahasiswa, maka semakin rendah stres yang dialami dan sebaliknya. Hal ini menunjukkan koping religius berperan menurunkan stres yang dialami oleh mahasiswa.

Koping religius digunakan individu dengan strategi kognitif atau perilaku yang didasarkan pada keyakinan dan praktek ritual religiusitasnya untuk memfasilitasi proses pemecahan masalah dalam mencegah atau meringankan dampak psikologis negatif dari situasi yang penuh stres dan hal ini membantu individu untuk beradaptasi dalam situasi kehidupan yang menekan (Koenig dalam Alflakseir \& Coleman, 2011). Koping religius mempengaruhi pola 
kognitif seseorang saat mencari solusi dalam menghadapi situasi sulit yang dialaminya dan dapat meningkatkan religiusitas seseorang (Pargament, 1997). Pengukuran koping religius telah terbukti sebagai prediktor yang lebih kuat saat menghadapi situasi yang penuh stres (Pargament dalam Ward, 2010).

Dalam ajaran Islam Islam keyakinan agama dan praktek-praktek religi dapat digunakan sebagai sumber daya untuk menghadapi situasi hidup yang sulit. Islam mengajarkan orang untuk bersabar, berdoa, percaya dan kembali kepada Tuhan saat membutuhkan bimbingan dan pertolongan. Kepercayaan Islam juga memberi individu penafsiran yang bermakna saat menghadapi situasi sulit. Keadaan yang sulit dalam kehidupan hanyalah untuk menguji orang-orang yang beriman, dan yang bersabar menghadapinya akan diberikan pertolongan dan kabar gembira (Alflakseir \& Coleman, 2011).

Pada penelitian ini, dari hasil analisis tambahan koping religius yang paling banyak dilakukan adalah penilaian kembali kebajikan (benevolent reappraisal), individu mengambil pelajaran dari masalah yang ada (mean = 18,35), kemudian praktek religius (religious praktis), individu fokus menjalankan praktek ajaran agama (mean $=17,53$ ), strategi koping aktif (active coping strategy), individu melakukan hal yang bisa dilakukannya dan menyerahkan sisanya pada Tuhan $($ mean $=10,00)$, perasaan negatif terhadap Tuhan (negative feeling toward God), individu merasa Tuhan telah melupakan dirinya (mean = 5,44 ) dan strategi koping pasif (passive religious coping strategy), individu hanya mengharapkan Tuhan untuk memecahkan masalahnya $($ mean $=5,00)$.

Umumnya saat menghadapi situasi yang menekan, individu mengambil pelajaran yang ada, kematian, penyakit, dan kerugian lainnya sebagai kehendak Tuhan atau kasih sayang Tuhan (Pargament, 1997). Demikian juga situasi stres yang dihadapi mahasiswa, selain itu mahasiswa juga lebih banyak menjalankan praktek ajaran agamanya. Hussain dan Cochrane (2003) mengemukakan praktek menjalankan ibadah merupakan kebutuhan yang tulus untuk meminta pertolongan kepada Tuhan.

Hussain dan Cochrane (2003) pada penelitiannya yang melibatkan subyek wanita muslim yang mengalami depresi mengemukakan bahwa koping yang bersifat religius merupakan strategi yang paling umum dilakukan, di mana mereka berdoa untuk mencari pertolongan dan membaca banyak doa-doa yang berasal dari Al-Qur'an terutama untuk meminta perlindungan dari penyakitnya dan simtom-simtom yang menyertainya. Beberapa dari mereka juga menyatakan bahwa kepatuhan menjalankan sholat lima waktu tetap dilakukan untuk menjadi muslim yang lebih baik. Selain itu mereka menganggap sholat sebagai kebutuhan yang tulus untuk meminta pertolongan.

Penelitian Utami (2012) dengan subjek mahasiswa, mengungkapkan bahwa mahasiswa yang cenderung menggunakan koping religius positif dalam menghadapi situasi tidak menyenangkan akan memaknainya secara positif dan ikhlas dalam menerima kenyataan, dengan cara melakukan ibadah (baik ibadah wajib waupun sunnah), menjauhi perbuatan maksiat, senantiasa untuk mematuhi 
semua ajaran Allah. Mahasiwa juga cenderung mendekatkan diri pada Allah, memohon dukungan, meminta kekuatan kepada Allah, dan meminta bantuan, dengan demikian, mahasiswa akan mampu untuk menahan amarah dan mengatasi kesedihan yang muncul.

Aspek koping religius diantaranya adalah religius praktis dimana individu cenderung melakukan ajaran agamanya seperti shalat dan berdoa ketika individu dihadapkan pada kondisi sulit yang dapat mengakibatkan stres, dengan melakukan hal tersebut individu dapat melewati masa-masa sulit yang ada, dan akan lebih mudah untuk melakukan penyesuaian diri. Active religious coping strategy, yaitu individu ketika dihadapkan pada masalah, individu akan cenderung melakukan penyelesaian masalah sebisa yang individu lakukan dan menyerahkan sisanya kepada Tuhan, kemudian religious benevolent reappraisal, yaitu individu juga dapat mengambil pelajaran dari masalah yang dihadapinya, dengan menanggapi sebuah permasalahan sebagai sesuatu yang bersifat baik, sehingga individu akan lebih mudah untuk melakukan proses penyesuaian diri(Aflakseir \& Coleman, 2010).

Day dan Pargament (dalam Ward, 2010) mengungkapkan strategi koping religius positif dikaitkan dengan peningkatan kesejahteraan. Senada dengan hal tersebut Harrison et.al. (dalam Marsella et.al., 2006) menyebutkan strategi koping religius positif, seperti mencari dan memberikan dukungan sosial, penilaian kembali dari situasi stres, dan gaya kolaboratif koping religius telah terbukti dengan kesehatan mental yang lebih baik. Sementara gaya koping religius negatif telah dihubungkan dengan peningkatan gejala depresi.

\section{KESIMPULAN}

Kesimpulan dari penelitian ini ada hubungan negatif yang signifikan antara koping religius denganstres mahasiswa, artinya semakin tinggi koping religius maka semakin rendah stres yang dialami dan sebaliknya.

Pada mahasiswa hendaknya dapat mempertahankan dan meningkatkan koping religius yang dimilikinya agar dapat menurunkan stres yang dialaminya.Para peneliti yang tertarik meneliti koping religius disarankan untuk membuat alat ukur koping religius dengan aitem-aitem yang lebih banyak dan diujicobakan terlebih dahulu agar mendapatkan alat ukur koping religius yang lebih sesuai dengan keadaan muslim di Indonesia.

\section{DAFTAR PUSTAKA}

Abraido-Lanza, A.F.,Vasques,E., \& Echeverria, S.E. (2004). En las Manos de Dios [in God's Hands]: Religious and other forms of coping among Latinos with arthritis. Journal of Consulting and Clinical Psychology, 72(1), 91102. 
Aflakseir, A., \& Coleman, P.G. 2011. Initial development of the Iranian religious coping scale. Journal of Muslim Mental Health, 6(1), 44-61.

Aldwin, R.S., Revenson, T.A. (1987). Does Coping Help? A reexamination of the relation between coping and mental health. Joutrnal of Personality and Social Psychology, 53(3), 337-348.

Boujut, E.,Koleck, M.,Bruchon-Scheitzer,M.,\& Bourgeois, M.L.(2009). Mental health among students: a study among a cohort of freshmen. Ann. Medico.Psychology, 167,662-668. 10.1016/j.amp.2008.05.020

Curtis, A.J. (2000). Health psychology. New York.

Crider, A.B., Goethals, G.R.,Kavanough, R.D., \& Solomon P.R. (1983). Psychology. New York: Scoot Foresman \& Co.

Feld, L.D. \& Shusterman, A. (2015). Into the pressure cooker : student stress in college preparatory high schools. Journal Adolescence, 41, 31-42.

Fink, L.D. (2003). Creating significant learning experiences. San Fransisco: John Willey \& Sons.

Ghorbani, N., Watson,P.J., \& Khan, Z.H. (2007). Theoritical, empirical, and potential ideological dimensions of using westren conceptualizations to measure Muslim religious commitments. Journal of Muslim Mental Health, 2, 113-131.

Hadi, S.(2000). Metodologi research jilid I. Yogyakarta: Andi Offset.

Hardjana, A.M. (2002). Stres tanpa distres:Seni mengolah stres. Yogyakarta: Kanisius.

Hawari, D. (2003). Prayer as medicine. Dzikir dan penyembuhan kanker : dzikir sebagai pelengkap terapi medis. Makalah Seminar. Tidak diterbitkan. Semarang: Lembkota.

Hussain, F.A., \& Cochrane, R. (2003). Living with depression : Coping strategies used by South Asian women living in the UK suffering from depression. Mental Health, Religion \& Culture, 2, 177-188.

Jana-Masri, A., \& Priester, P.E. (2007). The development and validation of a Qur'an based instrument to assess Islamic religiosity: The Religiosity of Islam Scale. Journal of Muslim Mental Health, 2, 177-188.

Khan, Z.H., \& Watson, P.J. (2006). Construction of the Pakistani Religious Coping Practices Scale: corelations with religious coping, religious orientation, and reactions to stress among Muslim university students. International Journal for the Psychology of Religion, 16, 10-112. 
RATNASUPRADEWI,Stres Mahasiswa Ditinjau dari Koping Religius

Khawaja, N.G. (2008). An ivestigation of the factor structure and psychometric properties of the COPE scale with a Muslim migrant population in Australia. Journal of Muslim Mental Health, 3, 177-191.

Koenig, H.G. (1994). Aging and God: Spiritual pathways to mental health in midlife and later years. New York: Haworth Pastoral.

Lazarus, R.S., \& Susan, F. (1984). Stress, appraisal, and coping. Michigan: Springer Publishing Company.

Lejoyeux, M., Richoux-Benhaim,C.,Lohnardt,H., \& Lequen,V. (2011). Money, attitude, self-esteem, and compulsive buying in a population of medical students. Addict.Disord.2,13.10.3389.fpsyt.2011.00013.

Lerik, M.C.D. (2004). Terapi musik untuk menurunkan simtom depresi pada mahasiswa. Tesis. Tidak diterbitkan. Yogyakarta: Fakultas Psikologi UGM.

Misra.R. \& Mckean.M. (2000). College student's academic stres and its realtion to their anxiety, time management, and leissure satisfaction. American Journal of Health Studies, 16 (1),41-45.

Marsella, A.J., Wong, P.T.P., \& Wong, L.C.J. (2006). Handbook of multicultural perspectives on stress and coping. USA: Springer.

Mehta, K.K. (1997). The impact of religious beliefs and practises on aging: A cross-cultural comparison. Journal of Aging Studies, 11, 101 - 114.

Pargament, K.I. (1997). The psychology of religion and coping. New York: Guilford Press.

Pargament, K.I., Koenig, H.G., \& Perez, L.M. (2000). The many methods of religious coping: Developmental and initial validation of the RCOPE. Journal of Clinical Psychology, 56, 519-543.

Pariat,L., Rynjah,A.,Joplin., \& Kharjana,G. (2014). Stress levels of college students: Interrelationship between stressors and coping strategies. Journal of Humanities and Social Science, 19(8), 40-46.

Raiya,A.H., Pargament, K.I., Stein, C., \& Mahoney, A. (2007). Lessons learned and challenges faced in developing the psychological measure of Islamic religiousness. Journal of Muslim Mental Health, 2, 133-154.

Rice, P.L. (1999). Stress and health. London: Brooks Cole Publishing Company.

Sarafino, E.P. (1998). Health psychology. Biopsychosocial Interaction. New York: John Wiley \& Sons, Inc.

Shelton, S. Spiritualitas kaum muda. Yogyakarta : Kanisius. 
Schraml,K., Perski, A., Grossi, G., \& Simonsson-Sarnecki, M. (2011). Stress symptoms among adolescents : the role of subjective psychological conditions, life style, and self-esteem. Journal Adolescence, 34, 987 - 996.

Siswanto. (2002). Kesehatan mental. Yogyakarta: Andi Offset.

Syukur, F. (2008). Modernisasi dan kenestapaan. http://Semarang news. Wordpress.com. Diakses 1 September 2018.

Supradewi, R. Efektivitas pelatihan dzikir untuk menurunkan stres dan afek negatif pada mahasiswa. Tesis. Tidak diterbitkan. Yogyakarta: Fakultas Psikologi UGM.

Taylor, S.E. (1995). Health psychology. New York: McGraw Hill, Inc.

Utami, M. S. (2012). Religiusitas, koping religius, dan kesejahteraan subjektif. Jurnal Psikologi, 39(1), 46-66.

Ward, A.M. (2010). The relationship between religiosity and religious coping to stress reactivity and psychological well-being. Dissertations. Georgia State University.s 